\title{
The Harmonic Response Analysis with Acoustic-vibration Coupling of the Combustion Chamber under Different Combustion Conditions
}

\author{
Min Zheng ${ }^{1}$, Fan Shen ${ }^{2}$ and Yiming $\mathrm{Xu}^{1}$ \\ ${ }^{1}$ College of Civil Aviation, Nanjing University of Aeronautics and Astronautics, 210014 Nanjing, China \\ ${ }^{2}$ Institution of Vibration Engineering, Nanjing University of Aeronautics and Astronautics 210014 Nanjing, China
}

\begin{abstract}
In this paper, numerical calculations of harmonic response with acoustic-vibration coupling of the combustion chamber under different combustion conditions has been performed by combining CFD and FEM methods. Temperature and sound pressure fields created by the flame in the combustion chamber are calculated first. And then the results of the CFD are exported to the FEM analysis for the interaction between acoustic waves and wall vibrations. The possible acoustic-vibration coupled eigenfrequencies at given combustion conditions are predicted by the harmonic response analysis.
\end{abstract}

\section{Introduction}

The interaction between combustion, acoustics and vibration of the combustion chamber walls will take place inside the combustion chamber. The unsteady heat release by the flame is an acoustic source. Driven noise is generated from the mutual interaction between flame aerodynamics and acoustic waves which increase vibrations of the liner. This behavior can lead to heavy thermo-acoustic instabilities and fatigue damage of the structural parts. Acoustics and structural vibrations are an inevitable outcome of a combustion process. The eigenfrequencies and mode shapes can be altered due to the change of combustion conditions. This paper investigates the acoustic-vibration harmonic response characteristics induced by premixed gas combustion under different combustion conditions. Computational Fluid Dynamics (CFD) analysis is performed, followed by the use of Finite Element Method (FEM).

\section{Acousto-vibration interaction}

The interaction between the fluid and structure at the interface includes the acoustic pressure exerting a force on the structure and the structural motion producing an effective fluid load, which ensures the exchange of the fluid and structural loads between acoustic and structure domains. The coupled acoustic and structural problem takes the following form [1]

$$
\left[\begin{array}{cc}
M_{S} & 0 \\
\rho_{0} R^{T} & M_{F}
\end{array}\right]\left[\begin{array}{l}
\ddot{U} \\
\ddot{P}
\end{array}\right]+\left[\begin{array}{cc}
C_{S} & 0 \\
0 & C_{F}
\end{array}\right]\left[\begin{array}{l}
\dot{U} \\
\dot{P}
\end{array}\right]+\left[\begin{array}{cc}
K_{S} & -R \\
0 & K_{F}
\end{array}\right]\left[\begin{array}{l}
U \\
P
\end{array}\right]=\left[\begin{array}{l}
F_{S} \\
F_{F}
\end{array}\right]
$$

where $P$ is the nodal pressure vector, $U$ is the nodal displacement vector, $M_{F}$ is the assembled fluid equivalent "mass" matrix, $K_{F}$ is the assembled fluid equivalent "stiffness" matrix, $M_{S}$ is the assembled structural mass matrix, $K_{S}$ is the assembled structural stiffness matrix, $\rho o$ is the density, and $R$ is the so-called coupling matrix in the interface surface. $F_{S}$ and $F_{F}$ are the structural and fluid load vectors, respectively.

\section{Computational fluid dynamics model}

A simplified annular combustor including three-layer structure, the combustor outer wall, the liner outer wall and the liner inner wall, is built in ProE software shown in Figure 1. Air as the oxidizer is injected along the axial direction at the annular zone between the outer wall and the inner wall of the liner. Fuel used here is methane and is injected from the side surfaces of the outer wall of the liner through 4 uniformly distributed holes in the annular direction near the left end shown in Figure 2. Both ends of the chamber are open. The geometry is imported into ANSYS 14.5 for the analysis. The dimensions of the combustor are listed in Table 1 and the material properties of the stainless steel are defined as shown in Table 2.

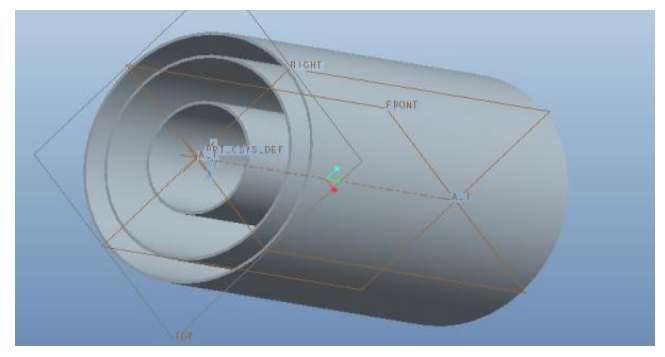

Figure 1. Geometry of the combustion chamber. 
Table 1. Geometry of the combustion chamber.

\begin{tabular}{|c|c|c|c|c|c|}
\hline & Length & $\begin{array}{c}\text { External } \\
\text { diameter }\end{array}$ & $\begin{array}{c}\text { Medium } \\
\text { diameter }\end{array}$ & $\begin{array}{c}\text { Internal } \\
\text { diameter }\end{array}$ & Thickness \\
\hline $\mathrm{mm}$ & 1000 & 800 & 650 & 350 & 4 \\
\hline
\end{tabular}

Table 2. Material properties of the stainless steel.

\begin{tabular}{|c|c|c|c|c|}
\hline & $\begin{array}{c}\text { Young's } \\
\text { modulus } \\
(\mathrm{N} / \mathrm{m} 2)\end{array}$ & $\begin{array}{c}\text { Poisson's } \\
\text { ratio }\end{array}$ & $\begin{array}{c}\text { Density } \\
{[\mathrm{kg} / \mathrm{m} 3]}\end{array}$ & $\begin{array}{c}\text { Thermal } \\
\text { expansion } \\
{[1 / \mathrm{c}]}\end{array}$ \\
\hline steel & $2.0 \mathrm{E} 11$ & 0.3 & 7200 & $1.0 \mathrm{E}-5$ \\
\hline
\end{tabular}

The fluid domain is filled with the gas between the outer wall and the inner wall of the liner as shown in Figure 3. A total number of 103726 unstructured tetrahedral elements and 19160 nodes shown in Figure are generated using the automatic meshing tool ANSYS Workbench 14.5 in this study.

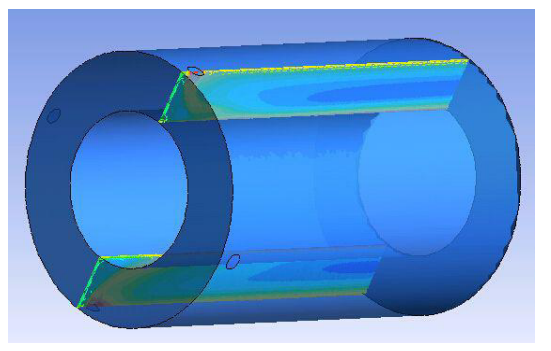

Figure 2. Selected cross section of the filled fluid.

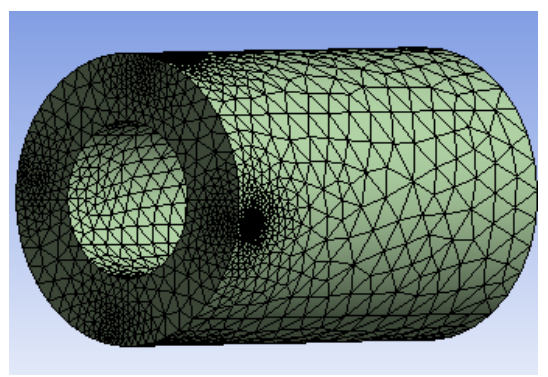

Figure 3. FEM model of the filled fluid.

When $300 K<T<2800 K$, by assuming that the thermal conduction coefficient of the fuel gases is a first-order polynomial function of temperature $T$, we can get[2]:

$$
\lambda_{s}=-4.040 \times 10^{-4}+8.515 \times 10^{-5} T
$$

In addition, it also can be assumed that the dynamic viscosity of the fuel gases is a third-order polynomial function of temperature $T$ as below:

$$
\begin{aligned}
\mu_{g}= & 2.957 \times 10^{-6}+5.039 \times 10^{-8} T \\
& -1.471 \times 10^{-11} T^{2}+2.517 \times 10^{-15} T^{3}
\end{aligned}
$$

Reacting flow simulations are carried out on the model combustor which are standard available in ANSYS CFX. In this study, non-premixed type of combustion occurs in the combustor simulation system. The methane
$\left(\mathrm{CH}_{4}\right)$ used as the fuel and the air are set at room temperature $300 \mathrm{~K}$ with no preheating and $700 \mathrm{~K}$ with preheating respectively. The flow parameters are set as shown in Table 3. The methane and the air have been assumed to react in accordance with a two-step reaction mechanism obeying the reactions:

$$
\begin{gathered}
\mathrm{CH}_{4}+3 / 2 \mathrm{O}_{2} \rightarrow \mathrm{CO}+2 \mathrm{H}_{2} \mathrm{O} \\
\mathrm{CO}+1 / 2 \mathrm{O}_{2} \rightarrow \mathrm{CO}_{2}
\end{gathered}
$$

Table 3. Operating conditions.

\begin{tabular}{|c|c|c|c|c|}
\hline Case & $\begin{array}{c}\text { Fuel flow } \\
\text { rate } / \mathrm{m} / \mathrm{s}\end{array}$ & $\begin{array}{c}\text { Air } \\
\text { velocity/ } \\
\mathrm{m} / \mathrm{s}\end{array}$ & $\begin{array}{c}\text { Fuel inlet } \\
\text { temperature/ } \\
\mathrm{K}\end{array}$ & $\begin{array}{c}\text { Air inlet } \\
\text { temperature } \\
/ \mathrm{K}\end{array}$ \\
\hline 1 & 40 & 10 & 300 & 300 \\
\hline 2 & 40 & 10 & 700 & 700 \\
\hline
\end{tabular}

The basic set of balance equations solved by ANSYSCFX comprises the continuity, momentum, species and energy transport. In this work k-Epsilon turbulent models and Eddy Dissipation combustion model are implemented. The combustion generated heat from the flame is transferred to the combustor structure by radiation and convection and conduction. The temperature profiles and sound power level profiles of the selected cross sections for the steady state are presented from Figure 4 to Figure 7.

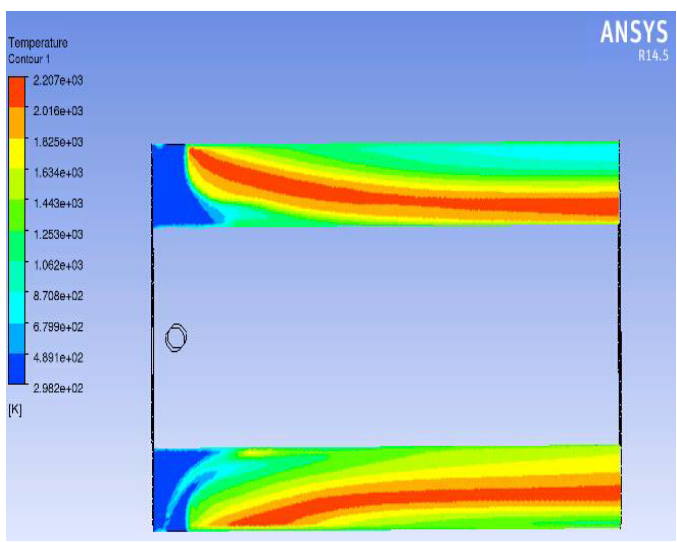

Figure 4. Temperature profile of the selected cross-section for Case 1.

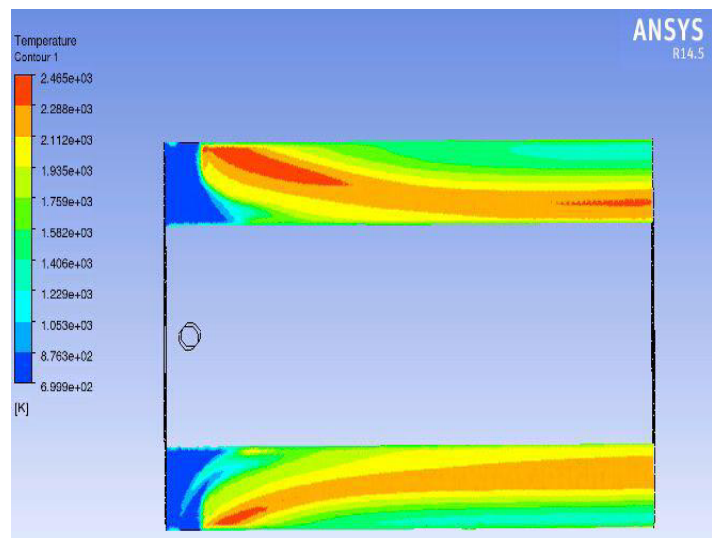

Figure 5. Temperature profile of the selected cross-section for Case 2. 


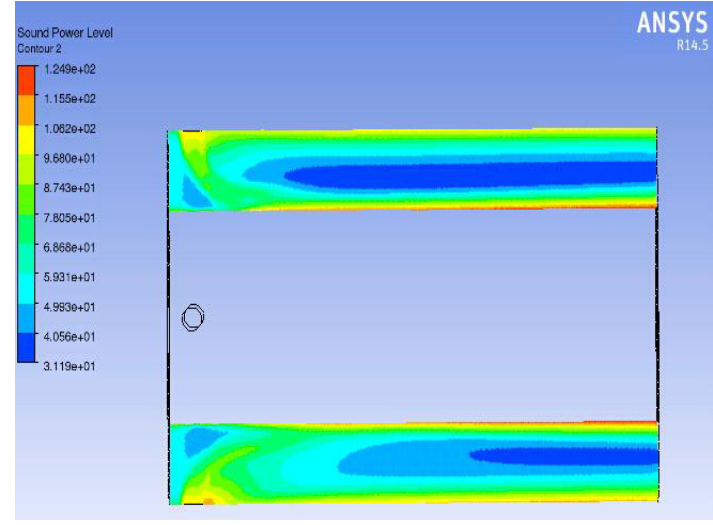

Figure 6. Sound power level profile of the selected crosssection for Case 1 .

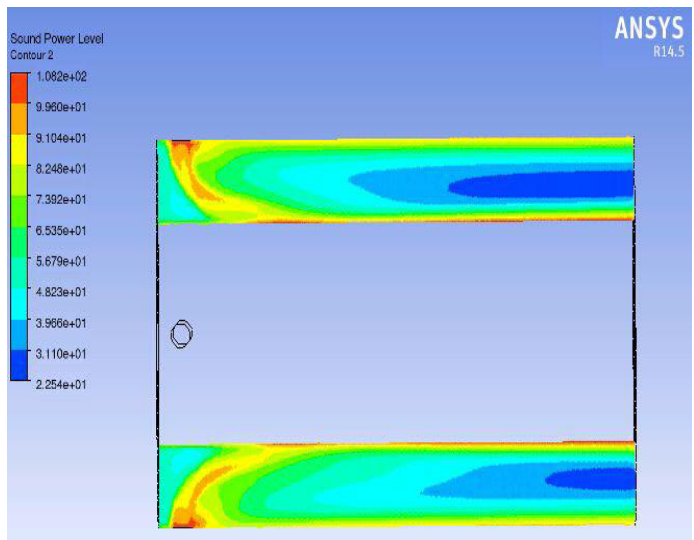

Figure 7. Sound power level profile of the selected crosssection for Case 2 .

\section{Acoustic-structure model}

The finite element solver available in the ANSYS suite of software is used for the calculation of the structural domain. The inlet end walls are set as the fixed support and an acoustically hard wall is imposed at the inlet. Three different types of elements are used. The crosssection of the numerical model with pointed different types of elements and connections is presented in Figure 8[3]. SHELL281 elements are employed for the structural modeling. The air cavities of the combustion chamber are represented by the FLUID30 acoustic elements. Two types of FLUID30 elements are used. The major part of the acoustic domain is modelled with uncoupled FLUID30 acoustic elements with keyopt(2) value equal to 1. One layer of the coupled FLUID30 elements with keyopt(2) value equal to 0 is placed next to the wall[4].

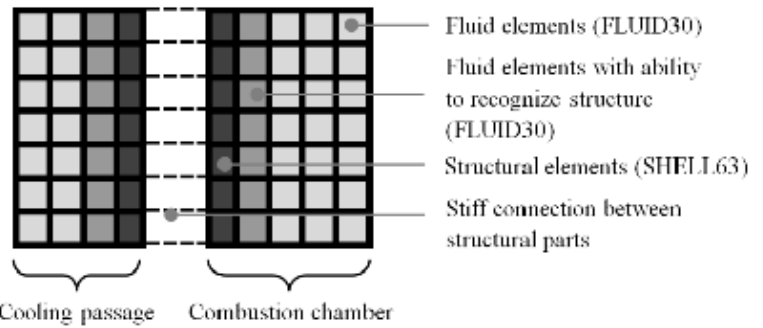

Figure 8. Transverse cross-section of the acousto-elastic model.
To simplify the analysis, a constant temperature and uniform material properties throughout all the mesh inside the structure were assumed. A numerical calculation is performed according to the average temperature field obtained in the previous CFD calculation during operating conditions, which is equal to $1250 \mathrm{~K}$ and $1580 \mathrm{~K}$ respectively. The material properties for acoustic elements are depicted in Table 4.

Table 4. Material properties of acoustic elements.

\begin{tabular}{|c|c|c|}
\hline Temperature $/ \mathrm{K}$ & 1250 & 1580 \\
\hline Density $/ \mathrm{kg} / \mathrm{m}^{3}$ & 0.2825 & 0.2235 \\
\hline Acoustic velocity m/s & 708 & 796 \\
\hline
\end{tabular}

The harmonic acoustic and the structural responses of the combustor system during the combustion process are described by full method. The acoustic pressure level at the fuel inlets from the previous steady state solution in the CFX calculations are fed into the acoustic-elastic model as the loads. A two-way coupling between acoustic pressure and structural motion at the interface is obtained by linking the transient modules and then transferring surface loads/displacements across the interface. This allows observing the impact of the wall vibration on the pressure distribution inside the combustion chamber as well as the effect of the modified pressure on the wall vibration.

\section{Results}

The sound power level and vibration of the liner wall within the range from $150 \mathrm{~Hz}$ to $550 \mathrm{~Hz}$ with the frequency time $5 \mathrm{~Hz}$ for the both investigated cases are calculated. The observed positions are selected at the middle point in the length direction on the liner outer wall and fluid respectively. The FSI numerical results for the spectrums of vibration displacements in the direction of $x$, $\mathrm{y}$, and $\mathrm{z}$-axis have been shown from Figure 9 to Figure 14 respectively. As can be seen in these Figures, the displacements in direction $\mathrm{x}$ and $\mathrm{y}$ are larger than those in direction z. An overview of the amplitude of the sound pressure fluctuation in the simulation, as a function of frequency is also shown in Figure 15 and Figure 16.

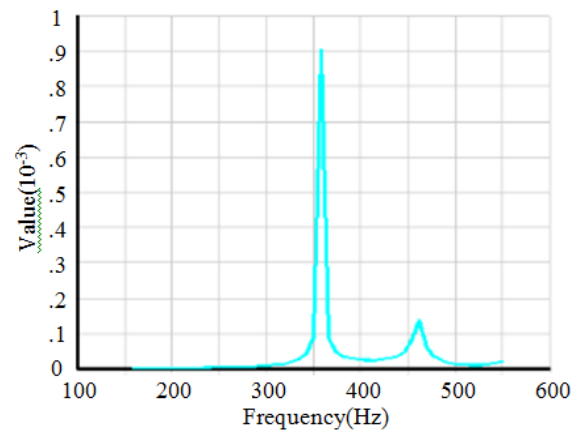

Figure 9. Frequency spectrum of vibration displacement in the $\mathrm{x}$ direction for Case 1 . 


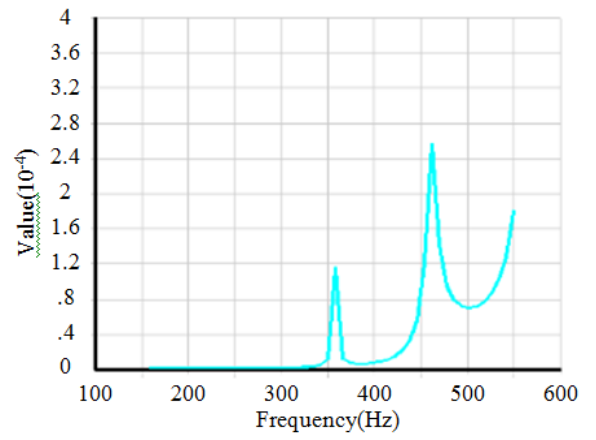

Figure 10. Frequency spectrum of vibration displacement in the y direction for Case 1.

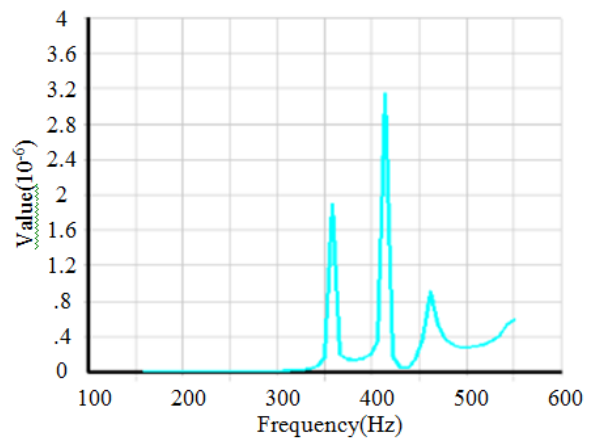

Figure 11. Frequency spectrum of vibration displacement in the $\mathrm{z}$ direction for Case 1 .

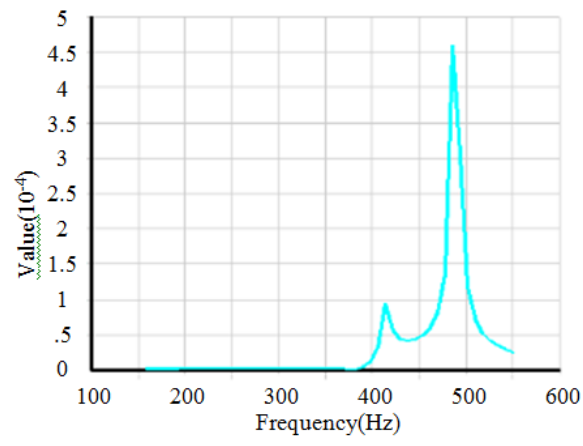

Figure 12. Frequency spectrum of vibration displacement in the $\mathrm{x}$ direction for Case 2 .

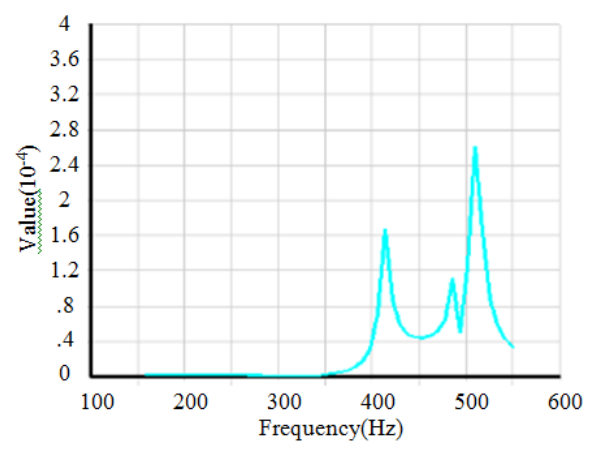

Figure 13. Frequency spectrum of vibration displacement in the y direction for Case 2.

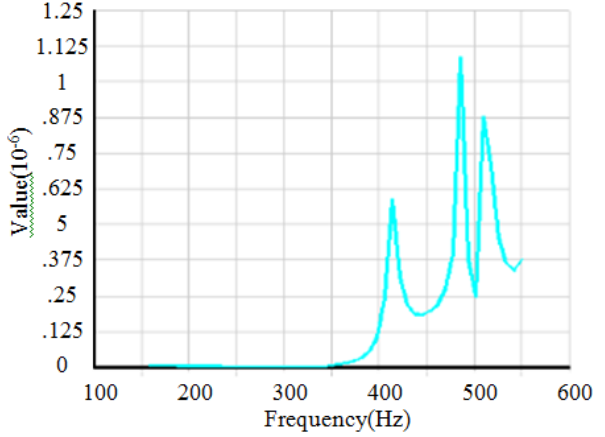

Figure 14. Frequency spectrum of vibration displacement in the $\mathrm{z}$ direction for Case 2 .

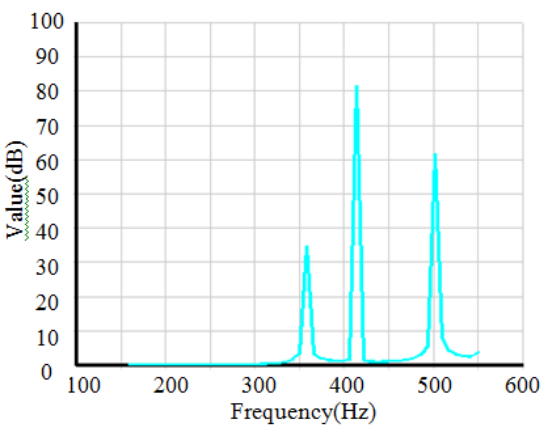

Figure 15. Frequency spectrum of sound power level harmonic response inside the combustion chamber for Case 1.

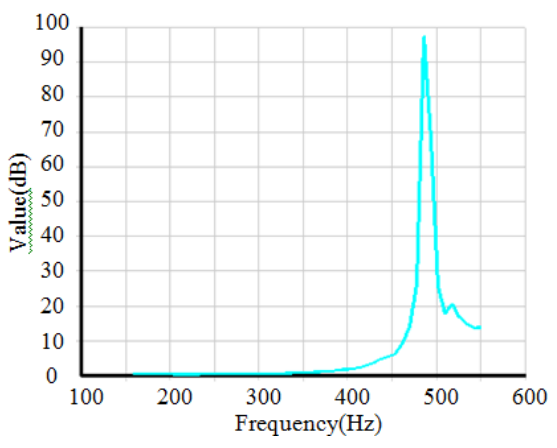

Figure 16. Frequency spectrum of sound power level harmonic response inside the combustion chamber for Case 2.

In case 1 , the modes around $355 \mathrm{~Hz}$ and $460 \mathrm{~Hz}$ are visible in all the spectra of vibration displacement. The forcing frequency of $410 \mathrm{~Hz}$ only appears in direction $\mathrm{z}$. It can be seen from Figure 15 that the acoustic frequencies at $355 \mathrm{~Hz}, 410 \mathrm{~Hz}$ and $500 \mathrm{~Hz}$ are visible. The main structural and acoustic eigenfrequencies intersect maybe happen at $355 \mathrm{~Hz}$ where the peak appears in all plots and $410 \mathrm{~Hz}$ where the peak appears in displacement frequency spectrum in direction $\mathrm{z}$ and acoustic frequency spectrum. They are hazardous for combustion systems because the acoustic and structural eigenfrequencies can be fed simultaneously and they can finally lead to unstable combustion and to liner failure. In case 2, the dominant peak around $480 \mathrm{~Hz}$ are visible in all the frequency spectra. At this frequency there is a significant coupling between acoustic mode and structural mode, thus the effect of pressure changes on the vibration pattern is significant. The peak at $510 \mathrm{~Hz}$ hardly visible in the displacement spectrum in direction $\mathrm{x}$ can be seen 
clearly in the other spectra. Therefore this frequency is also a coupled point where the structural and acoustic eigenfrequencies intersect. In addition, the eigenfrequencies in case 1 are different from those in case 2 which may be resulted from the different combustion conditions with the different temperature field.

\section{Conclusion}

Numerical investigation of the acoustic-vibration harmonic response characteristics has been performed in this paper for different combustion conditions. The temperature field and sound power level inside the combustion channel were calculated first by CFD analysis. Then obtained data were fed into FEM analysis for acoustic-vibration interaction prediction. The simulation results show that some coupled structural and acoustic eigenfrequencies exist. The combustion condition has a significant effect on the acousticvibration coupled characteristics of the combustion chamber.

\section{Acknowledgement}

This project is supported by National Natural Science Foundation of China (61179056) and Aeronautical Science Foundation of China (2013ZB52029).

\section{References}

1. ANSYS Mechanical APDL acoustic analysis guide Release 15.0, ANSYS Inc., Southpointe, (2013)

2. A. Pozarlik, J. B. W. Kok, "Numerical prediction of interaction between combustion, acoustics and vibration in gas turbines," in: Acoustics 2008 Paris, (2008), pp. 2749-2754.

3. A. Pozarlik, J. B. Kok, "Experimental Investigation and Numerical Prediction of Thermo-acoustic Instabilities and Associated Liner Vibrations Induced by Combustion Process in Gas Turbines," in 50th AIAA Aerospace Sciences Meeting including the New Horizons Forum and Aerospace Exposition, Nashville, (2012), pp. 1-17

4. Yan. Yuepeng, "Thermo-acoustic coupling analysis in combustion chamber under operating conditions", B.C. thesis, Dept. Civil Aviation Eng., Nanjing Aeronautics and Astronautics Univ., Nanjing, China, (2014) 